\title{
The Effects of Sintering Temperature and Agro Wastes on the Properties of Insulation Bricks
}

\author{
H. E. Mgbemere*, E. O. Obidiegwu, A. U. Ubong \\ Department of Metallurgical and Materials Engineering, University of Lagos, Akoka Lagos Nigeria.
}

ABSTRACT: In this research, kaolin, ball clay, sawdust and rice husk were used to produce insulation bricks through the solid state synthesis method. Two temperatures, $1100^{\circ} \mathrm{C}$ and $1200^{\circ} \mathrm{C}$ were used to sinter the green samples. X-ray fluorescence, scanning electron microscopy, compressive strength tests etc. were used to analyse the properties of the produced bricks. Chemical composition analysis on the starting raw materials showed that $\mathrm{SiO}_{2}$ and $\mathrm{Al}_{2} \mathrm{O}_{3}$ were the major constituents while $\mathrm{Fe}_{2} \mathrm{O}_{3}, \mathrm{Na}_{2} \mathrm{O}, \mathrm{K}_{2} \mathrm{O}$ and $\mathrm{TiO}_{2}$ were the minor constituents. As the amounts of kaolin used in preparing the samples decrease, the bulk density, modulus of rupture and cold crushing strength of the bricks decreases while the water absorption capacity, linear shrinkage increases. The thermal analysis showed that on heating the samples, the reactions were mainly exothermic with between 8 to $10 \mathrm{~mW} / \mathrm{mg}$ of heat released. The morphology of the samples showed that the pores began to collapse when the amount of kaolin present is below $70 \mathrm{wt}$. \%. Sintering the samples at $1100^{\circ} \mathrm{C}$ and $1200^{\circ} \mathrm{C}$ led to slightly different values in the results and is therefore very significant.

KEYWORDS: Insulation bricks, Kaolin, sawdust, rice husk, temperature effects

\section{INTRODUCTION}

Refractories are materials that can withstand the effect of abrasive or corrosive materials whether solids, liquids or gases at high temperatures. They can be inorganic, non-metallic in nature and depending on how porous they are, can be classified into two categories namely dense and porous refractories. The former is used where there is need for extreme mechanical, chemical or thermal stresses while the latter is usually for insulation applications because of their low thermal conductivity and heat capacity (Aramide, 2012). In the manufacture of porous refractories, raw materials like diatomite, perlite, expanded vermiculite, calcium silicate, fireclay, kaolin, quartz, alumina etc. are usually employed. Pore formers like sawdust, foam polystyrene, fine coke, binders etc. are usually introduced to produce porous bodies which lower the density and in turn the thermal conductivity of the brick.

There are a few reports of previous studies in the literature regarding the production of insulation bricks (Bogdanov et al., 2012, Bwayo and Obwoya, 2014, Pimraksa and Chindaprasirt, 2009, Ardeshir and Ahmadi, 2016). The effect of different amounts of sawdust on the properties of Ifon clay showed that the porosity of the samples increases with increasing sawdust content with a recommendation that sawdust amounts of *Corresponding author: hmgbemere@unilag.edu.ng between 10 and 15 wt.\% are required (Aramide, 2012). Sintering studies on insulation bricks made from a blend of purified clay, alumina and sawdust indicated that above $20 \%$ alumina content, the samples crumbled at elevated temperatures. It was therefore recommended that alumina content of $10 \%$ gives the properties required for insulation bricks (Folorunso et al., 2015a). The effect of particle size of the raw materials is to increase the thermal conductivity values provided the particle size is decreasing. The thermal conductivity of bricks formed from a mixture of kaolin, ball clay and sawdust indicates a reduction from $0.1428 \mathrm{w} / \mathrm{mK}$ to $0.0417 \mathrm{w} / \mathrm{mK}$ while the samples remained stable up to $1100^{\circ} \mathrm{C}$ (Viruthagiri et al., 2013).

Charcoal has also been used as an admixture to produce insulation bricks where the obtained density decreased by about $10 \%$ depending on the charcoal content in the bricks. A charcoal content of $10 \mathrm{wt} . \%$ in the bricks led to an increase in the water absorption capacity and porosity of the bricks (Phonphuak, 2013). Particulates from coconut shell used to produce insulation bricks showed that with $25-30 \mathrm{wt}$. \% of the additives, better mechanical properties were obtained (Esezobor et al., 2015). Clay and perlite used to produce high quality bricks showed that $24-30 \%$ of perlite gives the best thermal and physical properties (Topcu and Isikdag, 2007).

doi: http://dx.doi.org/10.4314/njtd.v17i2.6 
Expanded perlite as matrix, carboxy-methylcellulose (CMC) as a chemical binder, potassium borate $\left(\mathrm{K}_{2} \mathrm{~B}_{5} \mathrm{O}_{7}\right) /$ sodium borate $\left(\mathrm{Na}_{2} \mathrm{~B}_{5} \mathrm{O}_{7}\right)$ as natural binders and coal powder as additive have been used to produce insulation bricks. The compressive and flexural strength of the bricks were found to increase when aged from 2 to 90 days (Celik et al., 2014).

Aggregates of pumice, expanded perlite, borax, blend of molasses and hardener $\left(\mathrm{H}_{3} \mathrm{PO}_{4}-\mathrm{H}_{4} \mathrm{NO}_{3}\right)$ have been used to produce lightweight bricks. The $\mathrm{H}_{3} \mathrm{PO}_{4}$-hardened molassesbonded brick is preferred when $2.5 \%$ of borax was not used (Benk and Coban, 2012). 39.6\% pumice was found to be effective and increased the porosity of fired bricks while the density lowered to $1.58 \mathrm{~g} / \mathrm{cm}^{3}$ at $900^{\circ} \mathrm{C}$ and increased to 1.61 $\mathrm{g} / \mathrm{cm}^{3}$ at $1000^{\circ} \mathrm{C}$ respectively (Gencel, 2015). Lime, gypsum and diatomite used to produce bricks showed a positive correlation between lime content and strength/density of the bricks. A compressive strength of $17.5 \mathrm{MPa}$, density of 0.73 $\mathrm{g} / \mathrm{cm}^{3}$ and water absorption capacity of $46 \%$ were obtained (Pimraksa and Chindaprasirt, 2009). The use of paper pulp as an additive (15\% maximum) in the manufacture of insulation bricks led to a decrease in the thermal conductivity to 0.45 $\mathrm{W} / \mathrm{mk}$ which is about $60 \%$ enhancement in properties (Munoz et al., 2013).

Most of the insulation refractory bricks currently used in the country are imported meanwhile the raw materials necessary for making insulation bricks can be found in many parts of Nigeria. In this work, kaolin and ball clay have been used as the matrix materials while sawdust and rice husk are used as pore formers. The objectives of this research are to produce insulation bricks from locally available raw materials, to check the effect of sintering at different temperatures and to investigate the variation of rice husk and kaolin contents on the properties of the produced bricks.

\section{MATERIALS AND METHODS}

\section{A. Sample Preparation}

The starting raw materials used in the production of the insulation bricks are kaolin, ball clay, rice husk and sawdust. The kaolin was obtained from Darazo in Bauchi State, ball clay from Ikorodu in Lagos State, rice husk from Wushishi, Niger State and saw dust from Ebute Metta, Lagos State. In order to produce 5 different compositions of the insulating bricks, the amounts of the kaolin and rice husk were varied as shown in Table 1. The raw materials were first crushed in order to reduce them to smaller sizes. They were then measured and wet-mixed in the following proportions to produce 5 different compositions.
Table 1: Table showing the amounts of the different raw materials used in the production of the insulation bricks.

\begin{tabular}{lcccc}
\hline & \multicolumn{4}{c}{ Raw Materials } \\
\cline { 2 - 5 } Label & $\begin{array}{l}\text { Sawdust } \\
(\text { wt. \%) }\end{array}$ & $\begin{array}{l}\text { Ball clay } \\
(\text { wt. \%) }\end{array}$ & $\begin{array}{l}\text { Kaolin } \\
\text { (wt. \%) }\end{array}$ & $\begin{array}{l}\text { Rice Husk } \\
\text { (wt. \%) }\end{array}$ \\
\hline S1 & 5 & 5 & 90 & 0 \\
S2 & 5 & 5 & 80 & 10 \\
S3 & 5 & 5 & 70 & 20 \\
S4 & 5 & 5 & 60 & 30 \\
S5 & 5 & 5 & 50 & 40 \\
\hline \hline
\end{tabular}

The raw materials were ball milled until their average particle sizes were less than $150 \mu \mathrm{m}$. For ease of representation, the samples have been labelled The mixture was poured into already prepared moulds of dimensions $220 * 60 * 60 \mathrm{~mm}$ for the bricks and $60 * 60 * 20 \mathrm{~mm}$ for test samples and pressed to produce the green samples. 3 samples for each composition were produced in this study. The bricks were placed in an oven operating at $110^{\circ} \mathrm{C}$ and left to dry for 7 days and two temperatures, $1100^{\circ} \mathrm{C}$ and $1200^{\circ} \mathrm{C}$ were used to sinter the samples. The heating rate is $2^{\circ} \mathrm{C} / \mathrm{min}$ and the samples were held at these temperatures for $1 \mathrm{~h}$ and allowed to cool to room temperature in the furnace. A picture of the insulation bricks while still inside the oven is shown in Figure 1.
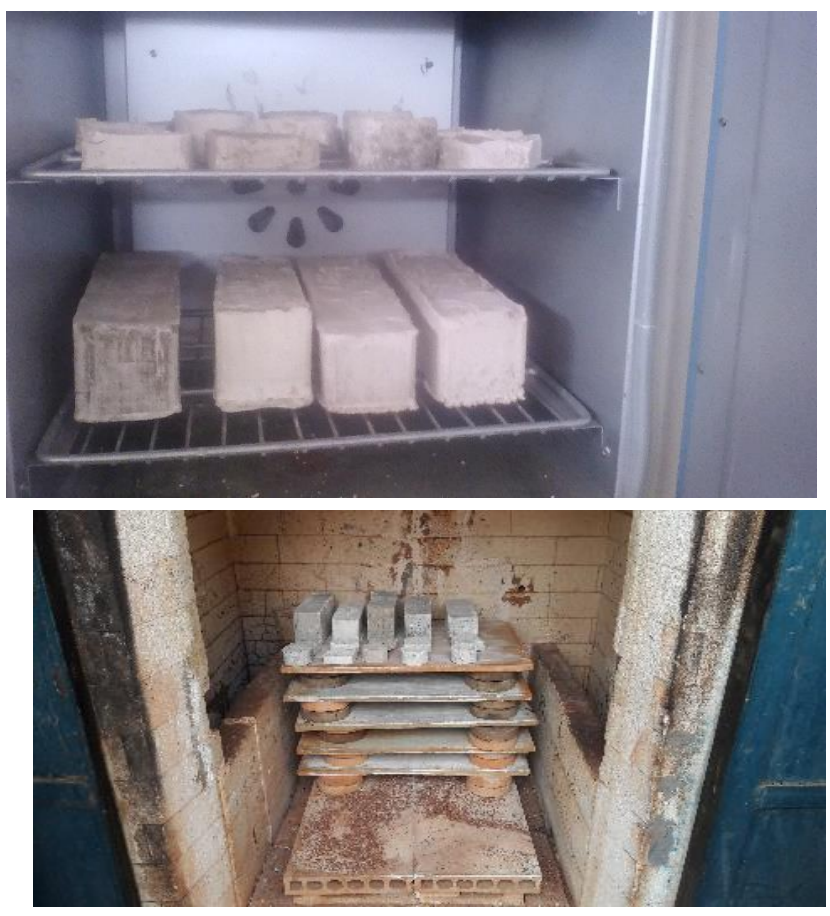

Figure 1: A picture showing the different sizes of the insulating refractory bricks (a) while still inside the oven at $110^{\circ} \mathrm{C}$ and (b) after sintering in the furnace. 


\section{B. Sample Characterisation}

The chemical composition analysis of the raw materials was determined with an X-ray Fluorescence Analyser at Venarum Scientific Materials Laboratory Limited Apapa, Lagos. The dimensions of the samples before and after sintering were measured and used to determine the physical properties of the bricks. To characterize the samples, a number of tests were carried out in accordance to the ASTM C13495(2016) and ASTM C20-00(2015) which are standard methods used to measure size, dimension, bulk density and apparent porosity, water absorption and shapes by boiling water respectively. The linear shrinkage (LS) of the samples were measured by measuring the length of the bricks before and after sintering and using the formula in eqn (1).

Linear Shrinkage $(\%)=\frac{D L-F L}{F L} * 100$

where $D_{L}$ stands for dry length and $\mathrm{F}_{\mathrm{L}}$ is fired length.

The apparent porosity (AP) of the samples was determined using the boiling water method. The sintered samples were put inside a water filled container and boiled for 2 hours, allowed to cool to room temperature after which they were removed and the porosity measured. The apparent porosity of each test specimen was calculated using eqn (2).

Apparent Porosity $(\%)=\frac{W-D}{W-S} * 100$

where: $\mathrm{D}=$ Weight of fired specimen, $\mathrm{S}=$ Weight of fired specimen suspended in water, and $\mathrm{W}=$ Weight of soaked specimen suspended in air.

For water absorption (WA) capacity tests, the weight of each sintered sample was recorded and then they were immersed in water at 30 and $45^{\circ} \mathrm{C}$ for $24 \mathrm{~h}$. The surfaces of the samples were dried and re-weighed after the immersion. The water absorption capacity of the samples was calculated using the formula in eqn (3).

WaterAbsorption $(\%)=\frac{W 2-W 1}{W 1} * 100$

where $\mathrm{W}_{1}=$ weight of dry specimen, $\mathrm{W}_{2}=$ weight of wet specimen after $24 \mathrm{~h}$ submersion in water.

The bulk density (BD) of the bricks was determined using the boiling water method. The Archimedes method was used to calculate the density by placing the samples in water, boiling for $2 \mathrm{~h}$ and subsequently allowing then to cool to room temperature. They were removed from the water, cleaned and re-weighed in air. The formula used to calculate the density is shown in eqn (4).

Bulk Density $=\frac{D}{W-S}$

where: $\mathrm{D}=$ Weight of fired specimen, $\mathrm{S}=$ Weight of fired specimen suspended in water, and $\mathrm{W}=$ Weight of soaked specimen suspended in air.

Modulus of Rupture (MOR) was carried out using a mechanical device where the specimens were placed on the bearing edges of the compression tester positioned $70 \mathrm{~mm}$ apart. Loads were then applied uniformly at the rate of 12.26 $\mathrm{N} / \mathrm{min}$ to the specimen until failure occurs; the formula used to calculate MOR is shown in eqn (5).

$M O R=\frac{3 W L}{2 b t 2}$

where $\mathrm{L}=$ the distance between bearing edges $(\mathrm{mm}), \mathrm{b}=$ width of the specimen $(\mathrm{mm}), \mathrm{t}=$ thickness of the specimen, and $\mathrm{W}=$ load at which the specimen failed.

The thermal analysis on the samples was carried out using a differential thermal analyser (DTA). The measurement was made on heating the samples from room temperature to $1100^{\circ} \mathrm{C}$. The cold crushing strength (CCS) of the samples was obtained by placing it between two plates on the compression tester and steadily increasing the compressive load applied to the specimen until it fails. The load value at which cracks begin to appear the bricks fails while operating at room temperature is the CCS. The CCS was calculated using the relation in eqn (6).

$$
C C S=\frac{\text { Maximum Load }(K N)}{\text { Cross Sectional Area }\left(m^{2}\right)}
$$

The compressive strength of the samples was determined using the cold compression strength test where the sintered samples were placed between two plates between the equipment followed by the application of a uniform load. The load where a visible crack appears on the sample is noted and divided with the cross sectional area of the sample. The morphology of the samples was measured with a scanning electron microscope (VEGA3 TESCAN, Czech Republic) at the Tshwane University of Technology, South Africa. The samples to be measured were prepared by sputtering their surface with carbon to ensure electrical contact. The energy dispersive X-ray spectroscopy (EDS) was obtained by selecting an area $50 * 50 \mathrm{~mm}$. The amounts of the quantitative EDS analysis (Oxford Instrument, UK) on the major elements present in the samples are shown. 


\section{RESULTS AND DISCUSSION}

\section{A. Presentation of Results}

The results of the chemical composition analysis on the raw materials are shown in Table $2 . \mathrm{SiO}_{2}$ is the main compound that is present in all the raw materials. Kaolin and ball clay contains significant amounts of $\mathrm{Al}_{2} \mathrm{O}_{3}$ while its quantity in the inorganic constituent of rice husk and sawdust are 4.49 wt. \% and 11.8 wt. $\%$ respectively. $\mathrm{Fe}_{2} \mathrm{O}_{3}$ is also present in all the raw materials as a minor constituent. The $\mathrm{SiO}_{2}$ and $\mathrm{Al}_{2} \mathrm{O}_{3}$ contents of kaolin are 51.38 and 42.05 wt. \% respectively and in ball clay, 63.59 and 23.37 wt. \% respectively. The impurities present in significant amounts in all the raw materials include $\mathrm{Fe}_{2} \mathrm{O}_{3}, \mathrm{Na}_{2} \mathrm{O}, \mathrm{K}_{2} \mathrm{O}$ and $\mathrm{TiO}_{2}$. They are present in amounts ranging from as low as 0.43 wt. \% to as high as 10.44 wt. \%.

The bulk density values as well as the linear shrinkage in the samples are shown in Figure 2. Samples sintered at $1100^{\circ} \mathrm{C}$ had slightly higher bulk density and lower linear shrinkage compared to those sintered at a temperature of $1200^{\circ} \mathrm{C}$. As the amount of kaolin present in the bricks decreased (increasing rice husk), the density of the samples decreased while the linear shrinkage values increased. When the kaolin content is $90 \mathrm{wt} . \%$, the density value is $1.49 \mathrm{~g} / \mathrm{cm}^{3}$ and increases to 1.61 $\mathrm{g} / \mathrm{cm}^{3}$ when it is 80 wt. \% before gradually decreasing to 1.24 $\mathrm{g} / \mathrm{cm}^{3}$ when the kaolin content is $50 \mathrm{wt}$. \%. The reason for this behaviour in density could be due to the volatile pore formers which escape leaving pores at their initial location. The density values in this work is similar to the literature report by (Folorunso et al., 2015a), (Chemani and Chemani, 2012) as well as (Tonnayopas et al., 2008) who obtained values between 1.4 and $1.6 \mathrm{~g} / \mathrm{cm}^{3}$ for their insulation bricks.

Sintering at both $1100^{\circ} \mathrm{C}$ and $1200^{\circ} \mathrm{C}$ respectively did not alter the trend in the linear shrinkage values. Sintering at $1200^{\circ} \mathrm{C}$ gave slightly higher linear shrinkage values compared to that at $1100^{\circ} \mathrm{C}$. Sintering at $1100^{\circ} \mathrm{C}$ resulted in shrinkage values ranging from $8.21 \%$ for $\mathrm{S} 1$ to $11.48 \%$ for $\mathrm{S} 5$ while the shrinkage at $1200^{\circ} \mathrm{C}$ is $8.23 \%$ for $\mathrm{S} 1$ to $11.91 \%$ for S5. It seems that kaolin inhibits shrinkage because the higher the kaolin content, the lower the shrinkage. This is slightly lower than

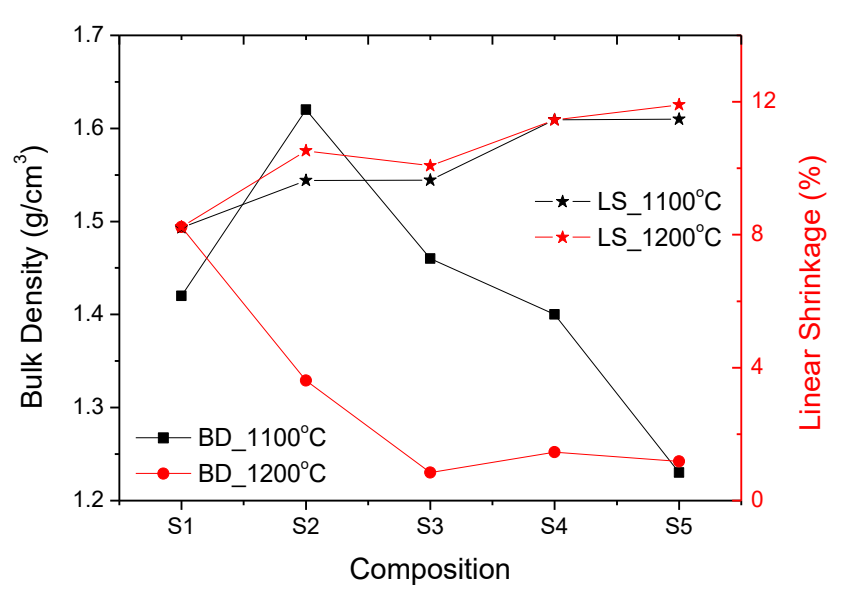

Figure 2: Graphs of bulk density and linear shrinkage (\%) as a function of composition of the insulation bricks.

the $14-17 \%$ reported by (Chemani and Chemani, 2012) for Clay-sawdust bricks but similar to that reported by (Ugheoke and Mamat, 2012).

The water absorption and apparent porosity values of the samples are shown in figure 2 . The samples sintered at $1100^{\circ} \mathrm{C}$ have a lower water absorption capacity compared to the samples sintered at $1200^{\circ} \mathrm{C}$. The observed trend is the increase in water absorption as the amount of rice husk increases. At $1100^{\circ} \mathrm{C}$, the water absorption value is $28.07 \%$ for sample $\mathrm{S} 1$ and gradually increases to $37.46 \%$ for sample S5. At $1200^{\circ} \mathrm{C}$, the value is $29.81 \%$ for sample $\mathrm{S} 1$ and gradually increases to $38.63 \%$ for sample S5. As the samples become more porous, the rate of water absorption increases.

The apparent porosity (\%) of the samples shows a gradual increase from sample $\mathrm{S} 1$ to sample $\mathrm{S} 3$ and a decrease in the values afterwards. For samples sintered at $1100^{\circ} \mathrm{C}$, the initial porosity was $24.25 \%$ and gradually increased to $29.87 \%$ before dropping to $27.55 \%$. For samples at $1200^{\circ} \mathrm{C}$, a similar trend was observed. For sample S1, the porosity value is $27 \%$ and gradually increased to $33 \%$ for sample S3 and decreases to $31.58 \%$. The reduction in porosity values with increasing amount of rice husk above $30 \mathrm{wt}$. $\%$ may be due to collapse in the pores structure within the samples.

Table 2: Chemical composition analysis of the raw powders using X-ray Fluorescence.

\begin{tabular}{|c|c|c|c|c|c|c|c|c|c|c|c|c|}
\hline $\begin{array}{l}\text { Composition } \\
\text { (wt. \%) }\end{array}$ & $\mathrm{SiO}_{2}$ & $\mathbf{A l}_{2} \mathbf{O}_{3}$ & $\mathrm{Fe}_{2} \mathrm{O}_{3}$ & MgO & $\mathrm{CaO}$ & $\mathrm{Na}_{2} \mathrm{O}$ & $\mathbf{K}_{2} \mathbf{O}$ & $\mathrm{TiO}_{2}$ & $\mathrm{BaO}$ & $\mathrm{ZnO}$ & $\mathbf{P}_{2} \mathbf{O}_{5}$ & MnO \\
\hline Kaolin & 51.38 & 42.05 & 1.39 & 0.02 & 0.16 & 1.73 & 0.43 & 2.37 & 0.001 & 0.005 & - & 0.007 \\
\hline Ball Clay & 63.59 & 23.37 & 3.02 & - & 0.57 & 0.87 & 1.18 & 0.93 & 0.039 & 0.001 & - & - \\
\hline Rice Husk & 68.85 & 4.49 & 3.56 & 1.36 & 5.33 & 0.68 & 10.44 & 1.01 & - & - & 1.04 & - \\
\hline Sawdust & 51.24 & 11.8 & 7.45 & 0.95 & 15.1 & - & 5.58 & 1.73 & - & 0.77 & 1.09 & - \\
\hline
\end{tabular}




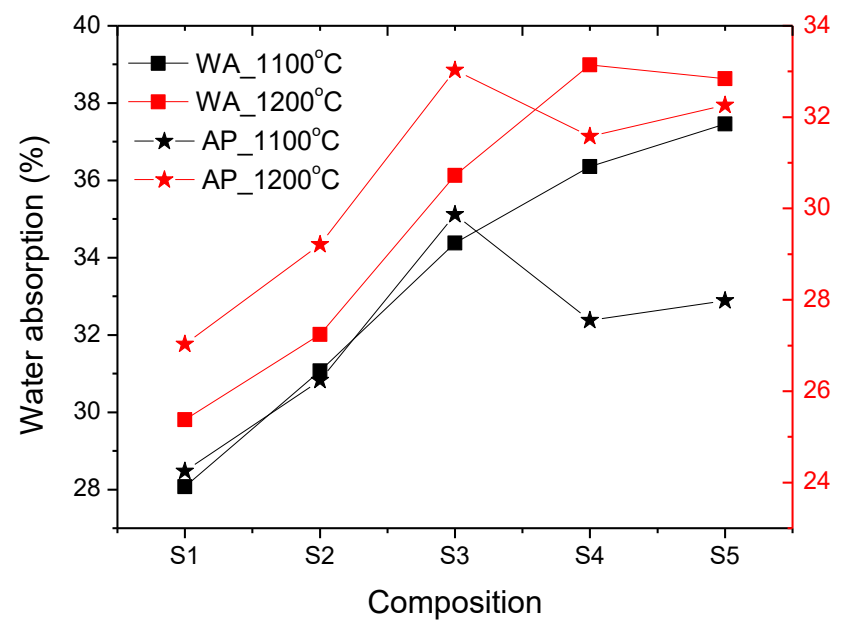

Figure 3: A plot of water absorption (\%) and apparent porosity (\%) as a function of sample composition.

Figure 4 shows the values of the modulus of rupture (MOR) and cold crushing strength (CCS) as a function of sample composition. The values of MOR generally decreased as a function of composition. Samples sintered at $1100^{\circ} \mathrm{C}$ generally have slightly higher values of MOR compared to samples sintered at $1200^{\circ} \mathrm{C}$. As the amount of rice husk added to the insulation brick increased, the MOR values decreased from 3.52 MPa for sample S1 to $1.76 \mathrm{MPa}$ for sample S5. The values of MOR for samples sintered at $1200^{\circ} \mathrm{C}$ followed the same trend from 3.18 MPa for sample S1 to 1.51 MPa for sample S5.

The values obtained in this research are similar to that reported by Folorunso et al., 2015 for bricks containing $\mathrm{Al}_{2} \mathrm{O}_{3}$ and sawdust (Folorunso et al., 2015b). The CCS values decreased with increasing rice husk content from 2.5 MPa to about $1 \mathrm{MPa}$. The value obtained here is about an order of magnitude lower than that reported for bricks produced using Clay and Rice husk ash (Tonnayopas et al., 2008). The difference in values could be due to differences in compositions used for the respective researches.

The plot of the thermal analysis as a function of composition using a differential thermal analyser is shown in Figure 5. The graph shows that the measurements for all the samples are in the exothermic range. At a temperature of about $50^{\circ} \mathrm{C}$, exothermic reactions could be observed and these continued until about $1000^{\circ} \mathrm{C}$. The explanation for this behaviour can be that as the samples are being heated; volatile or low melting temperature materials in the brick are gradually being burnt up giving up heat in the process. The trend in the thermal behaviour of the samples is similar for samples sintered at $1100^{\circ} \mathrm{C}$ and $1200^{\circ} \mathrm{C}$ respectively. As the quantity of pore formers in the bricks increase, the exothermic reactions increased.

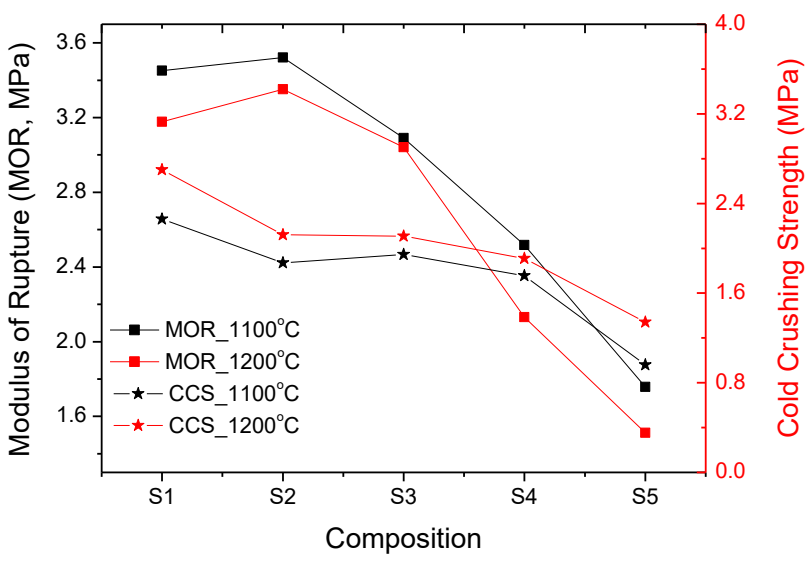

Figure 4: A graph of modulus of rupture (MOR) and cold crushing strength as a function of sample composition and sintering temperature.

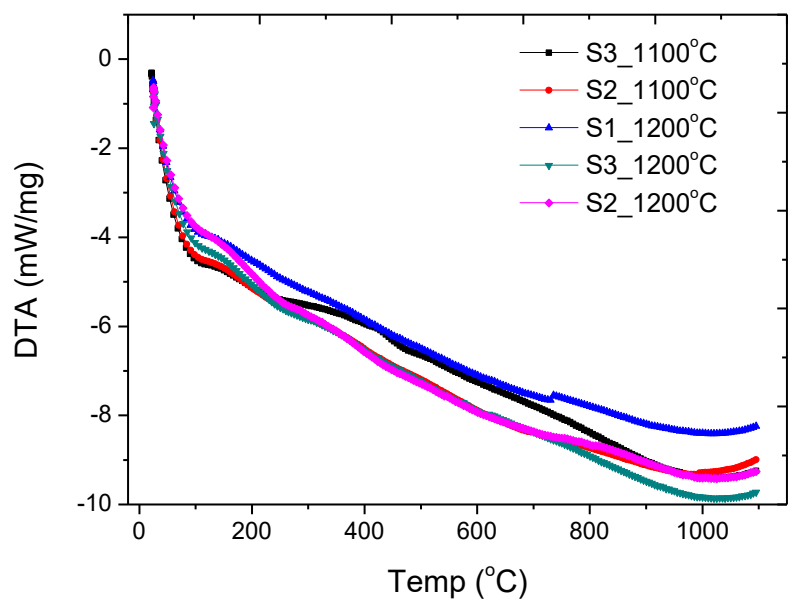

Figure 5: A plot of differential thermal Analysis (DTA) as a function of temperature for sintered at 1100 and $1200^{\circ} \mathrm{C}$ and measured on heating from room temperature.

The electron microscope images of the samples which reveal their morphology is shown in Figure 6. Two distinct phases with dark and bright features respectively can be observed in the micrographs. The microstructure of sample S1 reveals that in addition to the phases in the samples, pores could clearly be observed. As the amount of the pore formers increased in sample $\mathrm{S} 2$, the average size of the grains increased as well as the size of the pores. The size of the grains as well as the pores increased with higher amount of the pore formers in sample S3. As the amount of the pore formers increased further in samples S4 and S5, the size of the grains as well as the pores decreased. This observation is in agreement with the apparent porosity graph in Figure 3 where the porosity began 
to decrease after $20 \mathrm{wt}$. \% of rice husk. An explanation for this behaviour could be that with more pore formers, instead of the grains to further increase, the pores begin to collapse thereby decreasing the porosity in the samples.
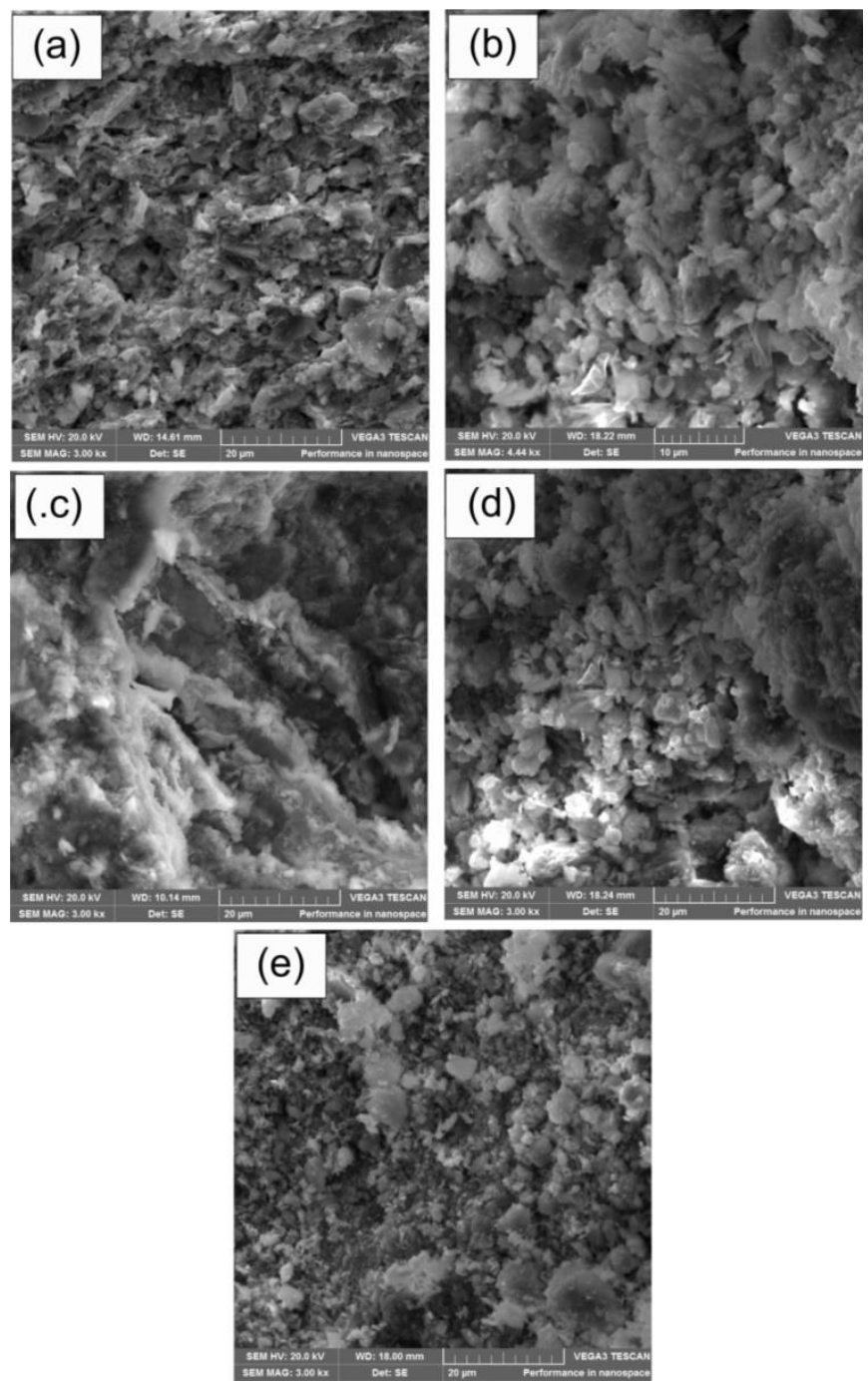

Figure 6: Scanning electron micrographs of samples (a) S1 to (e) S5 respectively sintered at $1100^{\circ} \mathrm{C}$.

Energy dispersive X-ray spectroscopy was carried out on the samples and a representative of the measurements is shown in Figure 7. An area scan of $50 \mu \mathrm{m}$ by $50 \mu \mathrm{m}$ was carried out to quantitatively determine the amounts of the major elements in the samples which are basically $\mathrm{O}, \mathrm{C}, \mathrm{Si}$ and $\mathrm{Al}$. The carbon is mainly from the coating to ensure electrical contact during the measurements. A summary of the quantitative analysis is shown in Table 3.

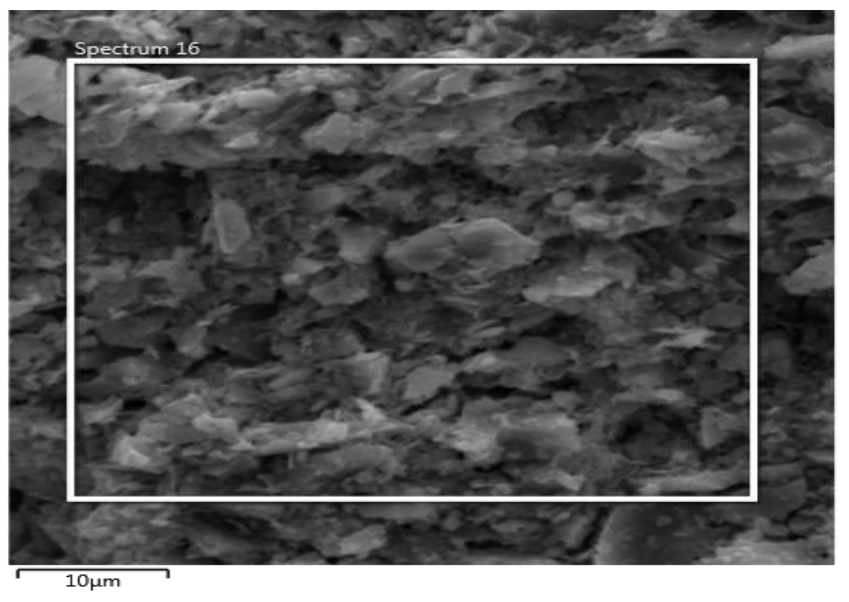

(a)

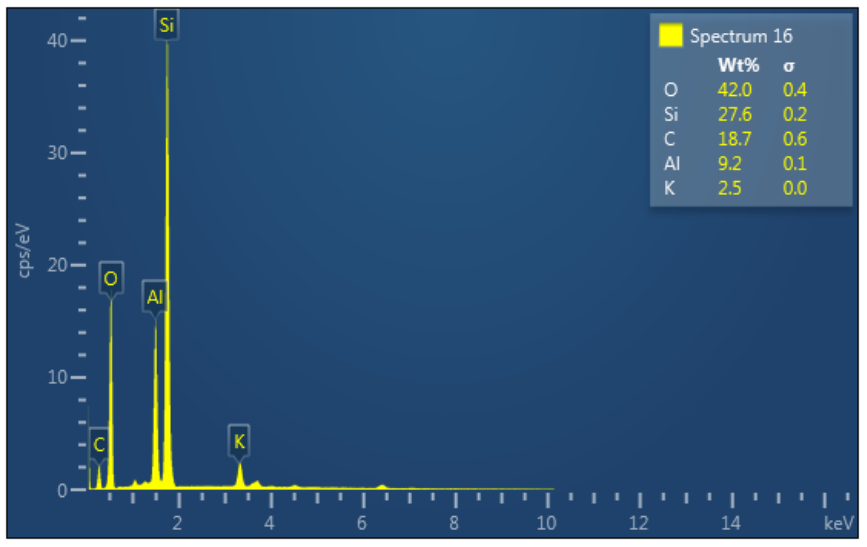

(b)

Figure 7: (a) Representative area scan of the energy dispersive X-ray spectrograph of the samples, and (b) the diffraction spectrum.

Table 3: Table showing the values of the quantitative energy dispersive $\mathrm{X}$-ray spectroscopy on the major elements present in the samples

\begin{tabular}{lcccccc}
\hline $\begin{array}{l}\text { Elements } \\
\text { (wt. \%) }\end{array}$ & & $\mathbf{O}$ & $\mathbf{S i}$ & $\mathbf{C}$ & $\mathbf{A l}$ & $\mathbf{K}$ \\
\hline & $\mathrm{S} 1$ & $42 \pm 0.4$ & $27.6 \pm 0.2$ & $18.7 \pm 0.6$ & $9.2 \pm 0.1$ & $2.5 \pm 0.0$ \\
& $\mathrm{~S} 2$ & $47.5 \pm 0.2$ & $42.2 \pm 0.1$ & - & $10.3 \pm 0.1$ & - \\
$\begin{array}{c}\text { Sample } \\
\text { Description }\end{array}$ & $\mathrm{S} 3$ & $45.9 \pm 0.3$ & $16.7 \pm 0.1$ & $20.5 \pm 0.4$ & $16.9 \pm 0.1$ & - \\
& $\mathrm{S} 4$ & $45.2 \pm 0.2$ & $16.5 \pm 0.1$ & $21.3 \pm 0.3$ & $17.1 \pm 0.1$ & - \\
& $\mathrm{S} 5$ & $46 \pm 0.2$ & $16.3 \pm 0.1$ & $21.1 \pm 0.3$ & $16.5 \pm 0.1$ & - \\
\hline \hline
\end{tabular}

The amounts of the elements in sample $\mathrm{S} 1$ show that silicon is $27.6 \%$ while $\mathrm{Al}$ is $9.2 \%$. Carbon was not detected in sample S2 which increased the silicon present to $42 \%$. Samples S3 to $\mathrm{S} 5$ are basically similar where the amount of silicon decreases to $16.5 \%$ while the $\mathrm{Al}$ increases to approximately $16.8 \%$. 


\section{CONCLUSION}

Investigation into the effect of sintering temperatures and the amounts of pore formers has been carried out in this research. The temperature of sintering has a slight effect on the physical and mechanical properties of the insulation bricks. The samples that were sintered at $1200^{\circ} \mathrm{C}$ had slightly better properties compared to those sintered at $1100^{\circ} \mathrm{C}$. As the amount of rice husk increases with decreasing kaolin content, the density values decreased from approximately $1.6 \mathrm{~g} / \mathrm{cm}^{3}$ to $1.2 \mathrm{~g} / \mathrm{cm}^{3}$.

The linear shrinkage, water absorption capacity, Apparent Porosity, Modulus of Rupture and Cold Crushing Strength of the bricks generally increased. It was observed that the Cold Crushing Strength and Water Absorption Capacity results were up to the standard required for refractory bricks. The SEM images show that the structure of the samples contained adequate pores for insulation. The pores however, begin to collapse when the amount of rice husk is more than $30 \mathrm{wt} . \%$. Great potentials therefore exist in the use of these raw materials to produce insulation bricks.

\section{REFERENCES}

Aramide, F. O. (2012). Production and Characterization of Porous Insulating Fired Bricks from Ifon Clay with varied Sawdust admixture. Journal of Minerals and Materials Characterization and Engineering, 11: 970-975.

Ardeshir, A. and Ahmadi, P. F. (2016). A synopsis about production of brick from lightweight and waste material - A Review. Computations and Materials in Civil Engineering, 1(3): 143-163.

ASTM C20 - 00 (2015). Standard Test Methods for Apparent Porosity, Water Absorption, Apparent Specific Gravity, and Bulk Density of Burned Refractory Brick and Shapes by Boiling Water. ASTM International, West Conshohocken, PA, 2015, www.astm.org

ASTM C134 - 95 (2016). Standard Test Methods for Size, Dimensional Measurements, and Bulk Density of Refractory Brick and Insulating Firebrick. ASTM International, West Conshohocken, PA, 2015, www.astm.org

Benk, A. and Coban, A. (2012). Possibility of producing lightweight, heat insulating bricks from pumice and $\mathrm{H}_{3} \mathrm{PO}_{4-}$ or $\mathrm{NH}_{4} \mathrm{NO}_{3}$-hardened molasses binder. Ceramics International, 38: 2283-2293.

Bogdanov, B.; I. Markovska; Y. Hristov and D. Georgiev. (2012). Lightweight Materials obtained by utilization of Agricultural Waste. International Journal of Chemical, Molecular, Nuclear, Materials and Metallurgical Engineering, 6(4): 332-335.

Bwayo, E. and Obwoya, S. K. (2014). Thermal Conductivity of Insulation Brick developed from Sawdust and selected Uganda Clays. International Journal of Research in Engineering and Technology, 3(9): 282-285.
Celik, A. G.; T. Depci and A. M. Kilic. (2014). New lightweight colemanite-added perlite brick and comparison of its physicomechanical properties with other commercial lightweight materials. Construction and Building Materials, 62: 59-66.

Chemani, B. and Chemani, H. (2012). Effect of adding sawdust on mechanical-physical properties of Ceramic Bricks to obtain lightweight building material. International Journal of Aerospace, Industrial, Mechatronic and Manufacturing Engineering, 6(11): 2521-2525.

Esezobor, D. E.; F. I. Apeh; M. O. Udo; M. Fabiyi and E. S. Apeh. (2015). Evaluation of cost effectiveness of Onibode Fire-Clay for production of high quality Refractory bricks. Journal of Minerals and Materials Characterization and Engineering, 3: 399-408.

Folorunso, D. O.; F. O. Aramide; P. Olubambi and J. O. Borode. (2015a). The effects of firing temperatures on the performance of insulating firebricks containing different proportions of Alumina and Sawdust. Journal of Minerals and Materials Characterization and Engineering, 3: 309-317.

Folorunso, D. O.; S. Aribo and O. Olaniran. (2015b). Performance evaluation of Insulating Firebricks produced from Hydrometallurgically purified Termite Hill Clay Reinforced with Alumina. American Journal of Engineering Research, 4(5): 1-7.

Gencel, O. (2015). Characteristics of fired clay bricks with pumice additive. Energy and Buildings, 102: 217-224.

Munoz, P.; M. C. Juarez; M. P. Morales and M. A. Mendivil. (2013). Improving the thermal transmittance of single-brick walls built of clay bricks lightened with paper pulp. Energy and Buildings, 59: 171-180.

Phonphuak, N. (2013). Effects of Additive on the Physical and Thermal Conductivity of Fired Clay Brick. Journal of Chemical Science and Technology, 2(2): 95-99.

Pimraksa, K. and Chindaprasirt, P. (2009). Lightweight Bricks of Diatomaceous Earth, Lime and Gypsum. Ceramics International, 35(1): 471-478.

Tonnayopas, D.; Tekasakul, P. and Jaritgnam, S. (2008). Effects of Rice husk ash on characteristics of lightweight clay brick. Technology and Innovation for Sustainable Development Conference (TISD2008). Thailand, Khon Kaen University.

Topcu, I. B. and Isikdag, B. (2007). Manufacture of high heat conductivity resistant clay bricks containing perlite. Buiding and Environment 42(10): 3540-3546.

Ugheoke, I. B. and Mamat, O. (2012). A critical assessment and new research directions of rice husk silica processing methods and properties. Maejo International Journal of Science and Technology, 6(3): 430-448.

Viruthagiri, G.; S. N. Nareshananda and N. Shanmugam (2013). Analysis of Insulating Fire Bricks for Mixtures of Clays with Sawdust Addition. Indian Journal of Applied Research, 3(6): 469-473. 